\title{
MEDINDO O DESEMPENHO DO PROCESSO DE INOVAÇÃO
}

$\star$ Herman F. Vantrappen

¿ Philip D. Metz

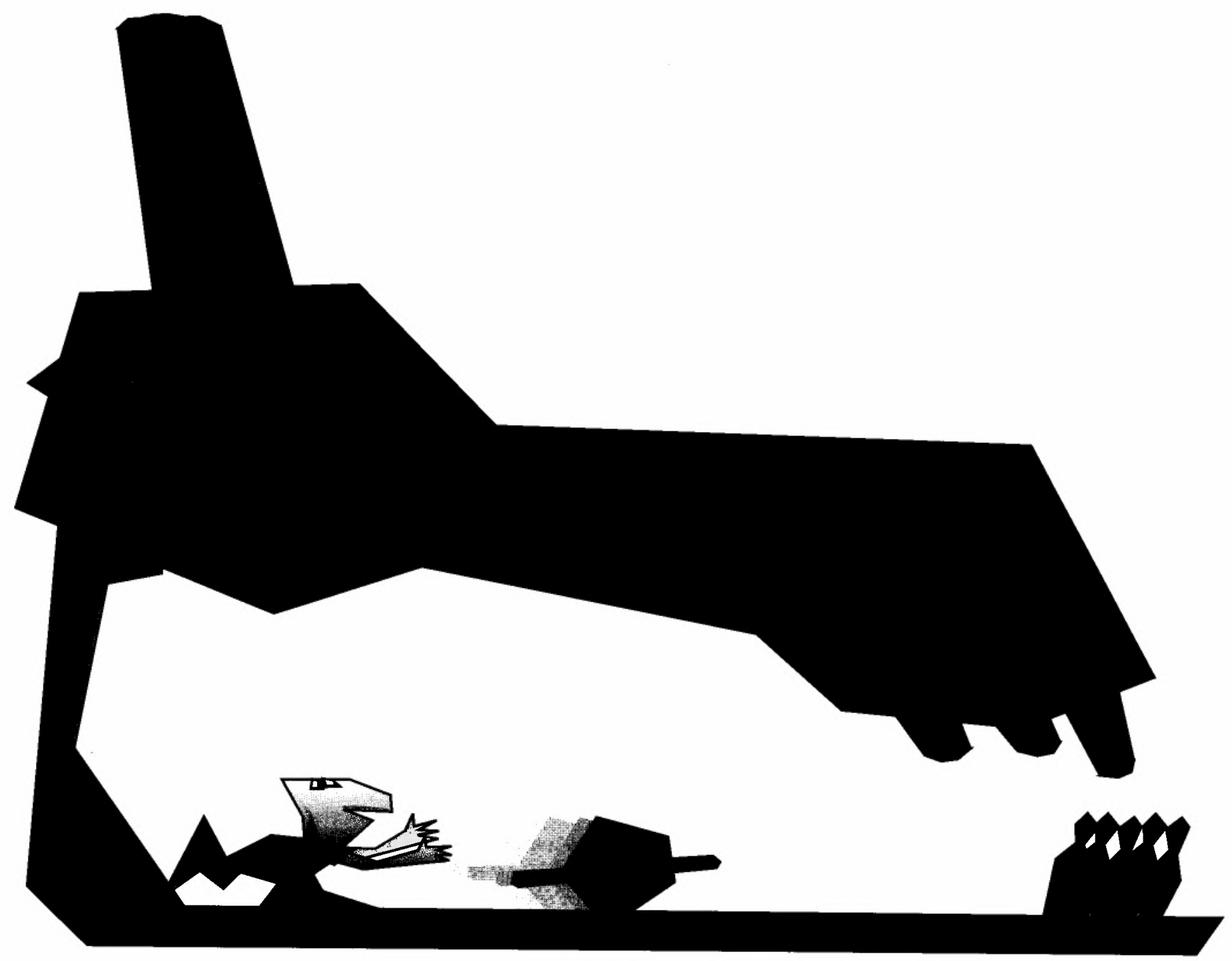

PALAVRAS-ChAVE:

Pesquisa \& desenvolvimento, indicadores de desempenho, processo de inovação, gestão da inovação, desenvolvimento de produtos, carteiras de projeto.

\section{KEY WORDS:}

Research \& development, performance indicators, innovation process, innovation management, product development.

$\star$ Diretor Adjunto do escritório da Arthur D. Little em Bruxelas.

Liretor Adjunto do escritório da Arthur D. Little em São Francisco. 


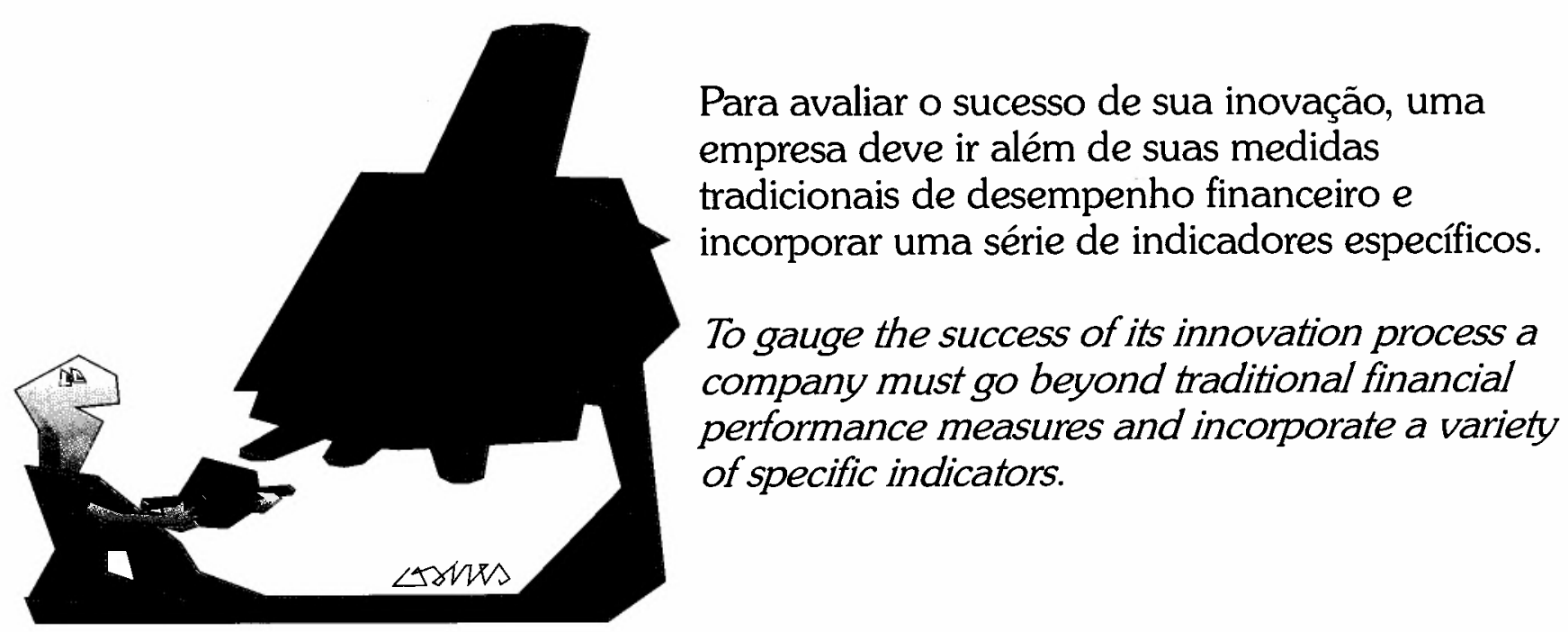

Q uando os executivos examinam até que ponto seu processo de inovação é dinâmico, a procura da parte essencial envolve questões de eficácia, eficiência e risco. Segundo os anais de sucesso da empresa, em termos de inovação, como ela tem enfrentado os concorrentes? A empresa tem obtido um retorno adequado de seus investimentos em tecnologia? O processo de inovação da empresa está suficientemente sob controle para melhorar a previsibilidade dos resultados?

As medidas de desempenho financeiro e os sistemas de contabilidade de custos tradicionais não respondem a essas questōes por quatro motivos:

- às vezes deixam de reconhecer que a inovação é um processo criativo, que não se presta a verificações de rotina;

- raramente fornecem padrões específicos de comparação para cada fase da cadeia de inovação, desde a pesquisa fundamental até o desenvolvimento incremental;

- freqüentemente consistem em indicadores situados "atrás", como fatia de mercado, ao passo que a administração de Pesquisa \& Desenvolvimento orientada para o futuro precisa de indicadores situados "à frente";

- tendem a ser muito agregados para ter um maior valor operacional, ou têm o foco muito estreito em funçōes individuais, como engenharia, para medir razoavelmente o desempenho do processo de inovação como um todo.
Os administradores precisam de um sistema de medição que lhes permita dirigir todo o processo de inovação, desde a idéia em gestação até o produto comercializável. O sistema também deve revelar as causas fundamentais de qualquer desempenho insuficiente, de modo que os administradores possam mudar adequadamente a forma como o processo de inovação vem sendo administrado. Para atingir esse objetivo, os administradores devem não-somente utilizar as medidas certas, mas fazêlo de forma correta.

Concluímos que os inovadores dinâmicos usam medidas corretas ao aderir a estes seis princípios:

- estabelecer uma parceria entre Negócio e Pesquisa \& Desenvolvimento;

- ligar os indicadores de desempenho à sua estratégia;

- utilizar um espectro de indicadores de desempenho;

- interpretar e ajustar continuamente os indicadores de desempenho;

- aprender a partir das medidas de desempenho e agir de acordo com elas;

- combinar as medições acionadas por calendário com análises acionadas por eventos.

\section{PARCERIA ENTRE NEGÓCIO E PESQUISA \& DESENVOLVIMENTO}

Os inovadores dinâmicos entendem que a medição do desempenho nunca pode ser um substitutivo para uma interface eficaz 
entre Negócio e Pesquisa \& Desenvolvimento. As empresas que não possuem essa interface às vezes recorrem a medidas de desempenho para "ajustar o rumo". A Pesquisa \& Desenvolvimento espera que as medidas de desempenho justifiquem suas inestimáveis iniciativas, embora o Negócio espere que as medidas de desempenho façam com que Pesquisa \& Desenvolvimento justifiquem seus gastos desproporcionais.

Nesses casos, a procura de medidas esconde uma falta de comunicação fundamental entre Negócio e Pesquisa \& Desenvolvimento. Como substitutas para uma interface efetiva, as medidas de desempenho serăo autodestrutivas. Os administradores "brincarăo com números" (o que não é difícil de fazer, com a tecnologia), o debate inútil sobre a interpretaçāo prevalecerá, e o Negócio ainda nāo estará convencido do valor da Pesquisa \& Desenvolvimento.

Conforme foi amplamente discutido num recém-publicado livro sobre Pesqui-

\section{O inovadores dinâmicos fomentam comunicações, criam uma linguagem comum e estabelecem objetivos conjuntos para Negócio e Pesquisa \& Desenvolvimento.}

1. ROUSELL, Philip A., SAAD, Kamal N, ERICKSON, Tamara F. Third generation Research \& Development: Managing the link to corporate strategy, Harvard Business School Press, 1991. fase de avaliaçāo e obtêm apoio e o pessoal necessário, enquanto as demais sāo descartadas. Mesmo assim, a empresa mede a qualidade das idéias descartadas de modo a avaliar sua vitalidade empresarial e estimular a parceria.

\section{LIGAÇÃO COM ESTRATÉGIA}

Os inovadores dinâmicos nāo selecionam aleatoriamente os indicadores de desempenho, mas sim os associam a sua estratégia. Estes indicadores devem refletir as metas e ambições da empresa de modo que esta possa acompanhar a eficiência com que persegue seus objetivos estratégicos.

Por exemplo, se a estratégia de produto da empresa exige uma rápida renovação do produto, um indicador significativo poderia ser o percentual de vendas derivadas de produtos apresentados ao mercado em determinado número de anos. $\mathrm{Na}$ Hewlett-Packard, mais de $60 \%$ das vendas sāo derivados de produtos apresentados nos últimos três anos. Os números correspondentes na $3 \mathrm{M}$ são $30 \%$ e quatro anos; na Baxter International, 34\% e cinco anos; na Emerson Electric, 20\% e cinco anos.

Se a estratégia de produtos da empresa está centrada no serviço pós-venda, uma medida-chave é o grau de orientaçāo que o projeto tem para a facilidade de manutençāo. No comércio de elevadores, por exemplo, onde a renda dos serviços compensa as baixas margens sobre as vendas originais de equipamentos, a manutençāo e os reparos são mais eficientes quando existem poucos modelos de produtos. Portanto, os indicadores que medem a modularidade e os aspectos comuns do projeto são muito mais úteis do que os que encorajam a novidade e a diversidade do produto.

Em uma desesperada tentativa de conseguir padrões de comparação quantitativos, as empresas podem ser tentadas a copiar os indicadores de desempenho "por atacado" de outra indústria ou empresa. Isso nāo só nāo significa nada, mas é perigoso, uma vez que indicadores inapropriados podem conduzir a comportamentos em direções contrárias aos objetivos das empresas. 


\section{ESPECTRO DOS INDICADORES}

Os inovadores dinâmicos nâo utilizam um indicador para todos os fins, mas um espectro de indicadores que refletem a complexidade e importância da tecnologia e inovaçăo. Um de nossos clientes, uma grande empresa do setor químico, recentemente contratou como chefe de sua Divisão Central de Pesquisas um controlador que veio do setor de seguros de vida. Quando começamos a trabalhar com ele para desenvolver um sistema de indicadores de desempenho, ele estava determinado a conseguir uma superfórmula individual que lhe dissesse como a Divisão de Pesquisa estava operando. Posteriores discussões com essa Divisão e seus clientes, isto é, as unidades comerciais da empresa, o convenceram a abandonar o plano de sua superfórmula em favor de um conjunto muito mais significativo e balanceado de indicadores.

Conforme é mostrado na figura 1 , os inovadores dinâmicos ampliaranı o espectro dos indicadores de desempenho em quatro dimensões.

\section{Pesquisa \& Desenvolvimento} incremental e Pesquisa \& Desenvolvimento fundamental

Os inovadores dinâmicos medem não somente sua agilidade em explorar o conhecimento existente (Pesquisa \& Desenvolvimento incremental), mas também a forma como criam o conhecimento, que é novo para a empresa e até para o mundo (Pesquisa \& Desenvolvimento fundamental). A medição da eficácia da Pesquisa \& Desenvolvimento incremental é relativamente fácil: você simplesmente compara o desempenho atual com objetivos como custo de produto, orçamento do projeto, percentual de componentes executados a partir de um desenho anterior, e velocidade de penetração no mercado.

Os indicadores para a Pesquisa \& Desenvolvimento fundamental devem medir como a empresa amplia ou aprofunda sua capacidade técnica. Algumas empresas instalam um "controle da balança comercial" das exportaçôes e importaçôes de licenças em seu centro de Pesquisa \& Desenvolvimento fundamental, quer seja com relação a outras partes da empresa ou

\section{Figura 1}

\begin{tabular}{|l|l|}
\hline $\begin{array}{l}\text { Espectro dos indicadores de desempenho } \\
\text { Enfoque tradicional }\end{array}$ & \begin{tabular}{l} 
Enfoque dinâmico \\
\hline $\begin{array}{l}\text { Pesquisa \& Desenvolvimento } \\
\text { Incremental }\end{array}$
\end{tabular} \\
\hline Projeto Individual & $\begin{array}{l}\text { Pesquisa \& Desenvolvimento } \\
\text { fundamental }\end{array}$ \\
\hline Indicadores "atràs" & Carteira de projetos \\
\hline Administraçāo sênior
\end{tabular}

a terceiros. Outras, como a empresa farmacêutica Merck, usam análises de opçāo financeira para avaliar os retornos dos projetos estratégicos a longo prazo com um alto grau de incerteza e recursos financeiros escalonados.

\section{Projetos individuais e carteiras de projetos}

Os inovadores dinâmicos medem a eficiência não-somente dos projetos individuais de desenvolvimento, mas também da carteira de projetos, como um todo. Alguns indicadores mostram como os projetos individuais são executados em função do tempo de desenvolvimento "à frente", número de mudanças tardias de engenharia, problemas com o produto após o lançamento ou outros aspectos operacionais.

Os indicadores da carteira de projetos de Pesquisa \& Desenvolvimento mostram como efetivamente ela suporta a estratégia de negócio e até que ponto é equilibrada em termos da recompensa esperada,

\section{Os inovadores dinâmicos não selecionam aleatoriamente os indicadores de desempenho, mas sim os associam à sua estratégia.}

incerteza tecnológica ou comercial, ou tempo para chegar ao mercado. Um de nossos clientes do setor siderúrgico avalia sistematicamente o trampolim potencial de cada projeto de Pesquisa \& Desenvolvimento proposto. Mesmo que um proje- 


\section{Figura 2}

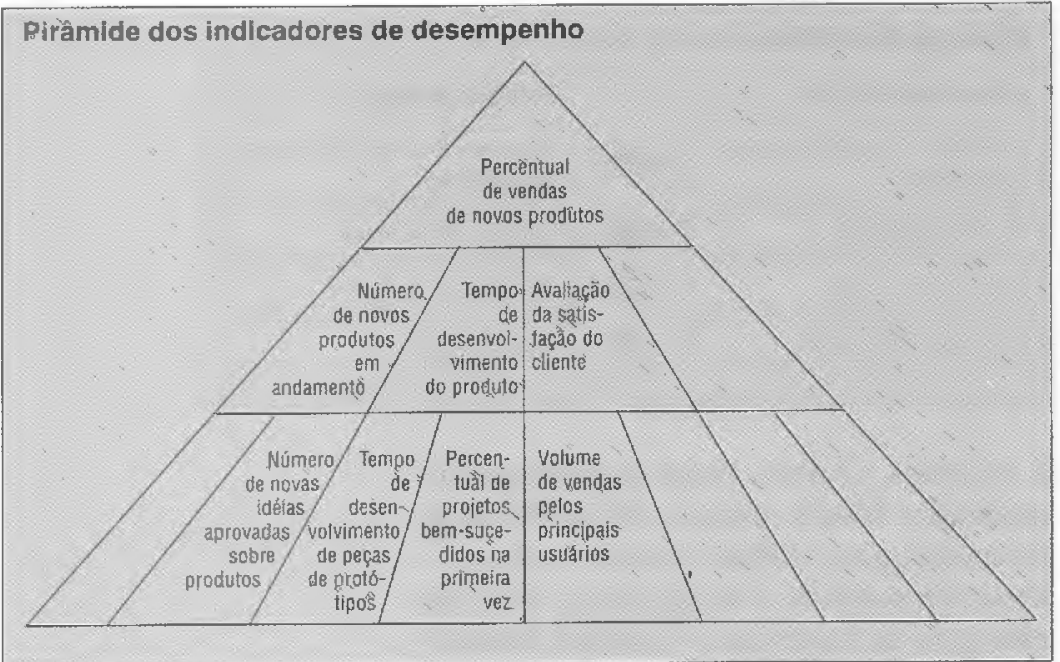

to em si mesmo náo mereça ser iniciado, pode ser digno de ser levado adiante se fornecer uma plataforma para outros projetos em carteira.

Os indicadores da carteira podem mostrar também a forma como a carteira das novas idéias é administrada. Um indicador que ajuda a Hewlett-Packard a medir a eficiência de sua geração de projetos é "o desperdício na mudança da equipe de

\section{Os inovadores dinâmicos não aplicam mecanicamente o sistema de indicadores, utilizam os indicadores de forma flexivel e permitem interpretação e ajuste continuos.}

projetos" : o custo de tempo e recursos gastos entre o final do projeto anterior e o ponto em que os membros da equipe estarão outra vez totalmente envolvidos em atividades que geram valor.

\section{Indicadores "atrás" e indicadores "à frente" \\ Ao medir os indicadores "à frente", os inovadores dinâmicos avaliam a forma}

como foi gasto o dinheiro alocado para a inovação. Para esta avaliação após o fato, eles usam indicadores "atrás", como ciclotempo de desenvolvimento, qualidade inicial do produto, custos de garantia, volume de vendas do primeiro ano e horas de pesquisa cobráveis. Esses indicadores de fim de processo permitem-lhes traçar os progressos no tempo, criar um referencial de desempenho e identificar sintomas de um processo de inovaçāo de mau desempenho.

Contudo, os inovadores dinâmicos também entendem que os indicadores situados "atrás" não đão os primeiros sinais de alarme, não esclarecem as causas fundamentais nem permitem ação corretiva. " $A$ tecnologia e o negócio nāo estão necessariamente em sintonia, no ciclo das coisas", disse um participante em um recente colóquio da Arthur D. Little. "A visāo da tecnologia é difícil porque quando um negócio está caminhando bem, é baseado em uma tecnologia de ontem. Há uma combinação inadequada. As sementes da destruição estão plantadas no auge do sucesso. A história às vezes é o pior inimigo no mapeamento do futuro".

Portanto, os inovadores dinâmicos acrescentam indicadores "à frente", que medem, por exemplo, o tempo necessário ao equilibrio, a qualidade do planejamento, a conformidade com a melhor prática, o tempo gasto com clientes, a pontualidade nas entregas, a abrangência das análises iniciais de engenharia e a qualidade dos recursos.

\section{Administração sênior e áreas básicas}

Os inovadores dinâmicos também se certificam de que todos os níveis da organização usem indicadores relevantes de desempenho. Ao nível da administração sênior, os indicadores agregados, como o percentual de vendas de novos produtos, fornecem um critério para o estado do processo de inovação çomo um todo. Esses indicadores agregados, contudo, não mostram onde nem como melhorar o processo de inovação nas atividades diárias. Para isso, são necessários indicadores básicos, como o tempo para se obter peças de um protótipo. Além disso, os inovadores dinâmicos ligam os indicadores em vários níveis lógicos, como em uma pirâmide, de modo que as prioridades estabelecidas no topo dirijam o comportamento da parte 
inferior, e o bom desempenho na parte inferior siga até o topo (ver figura 2).

\section{INTERPRETAÇÃO E AJUSTE}

Uma vez que o espectro dos indicadores de desempenho ligados à estratégia da companhia está no lugar, a medição e o acompanhamento podem ser iniciados. Contudo, os inovadores dinâmicos não aplicam mecanicamente o sistema de indicadores. Utilizam os indicadores de forma flexível e permitem interpretação e ajuste contínuos.

Algumas das diretrizes que eles seguem sāo:

- definir metas ousadas porém realistas para cada indicador de desempenho. As metas ousadas usualmente geram primeiro desespero e depois irritação. A "prova dos nove" de seu realismo é se a irritação posteriormente é transformada em obstinação. Uma vez esclarecido o obstáculo, a equipe de trabalho, a criatividade extraordinária e finalmente o sucesso seguem naturalmente;

- sintonizar a freqüêencia de medição à velocidade de mudança do processo. Uma frequência muito alta cria fadiga de indicador pela falta de variaçāo; uma frequiência muito baixa deixa as ameaças e oportunidades passarem despercebidas - ou serem percebidas tarde demais. Da mesma forma, ajustar as metas e a escala de medição às melhorias que ocorrem. Mostrar como mudam essas metas e como o desempenho melhora com o decorrer do tempo;

- manter as pessoas responsáveis pelo desempenho do indicador enquanto possam influenciar os resultados. Uma pirâmide de indicadores de desempenho, conforme foi anteriormente discutido, pode ser muito eficaz. Além disso, recompensar o bom desempenho, levando em consideraçăo recompensas individuais assim como por equipes; considerando recompensas para os donos de processos e para os líderes, bem como para os gerentes funcionais.

\section{APRENDIZADO E ATUAÇÃO}

A Corning usa seu "Million Dollar $\mathrm{Club}^{\prime \prime}$ para identificar sistematicamente quais os projetos de pesquisa executados há sete anos que estão agora produzindo no mínimo US\$1 milhão anualmente em receita. Ela investiga e aprende a partir de projetos tanto de dentro como de fora do clube. Os inovadores dinâmicos, como a Corning, entendem que a medição do de-

\section{Os inovadores dinâmicos, como a Corning. entendem que a medição do desempenho é inútil a menos que acelere o aprendizado.}

sempenho é inútil a menos que acelere o aprendizado. Só é razoável medir o desempenho quando ele "dispara" o entendimento e elimina os acionadores de mau desempenho.

Vamos supor, por exemplo, que um gerente esteja preocupado com o desempenho errático do tempo de desenvolvimento de seus projetos novos. Em alguns períodos, a maioria dos projetos acaba cumprindo o cronograma planejado; em outros períodos, um grande número de projetos acaba bem alem do planejado (ver figura 3 ). Uma visão mais ampla revela uma correlação entre a complexidade e o desempenho. Assim que o número médio de projetos nos quais os engenheiros trabalham simultaneamente se eleva acima de um determinado nível, os problemas de coordenação e longo tempo de instalaçāo lançam o processo de inovação em um caos inadministrável.

\section{Figura 3}

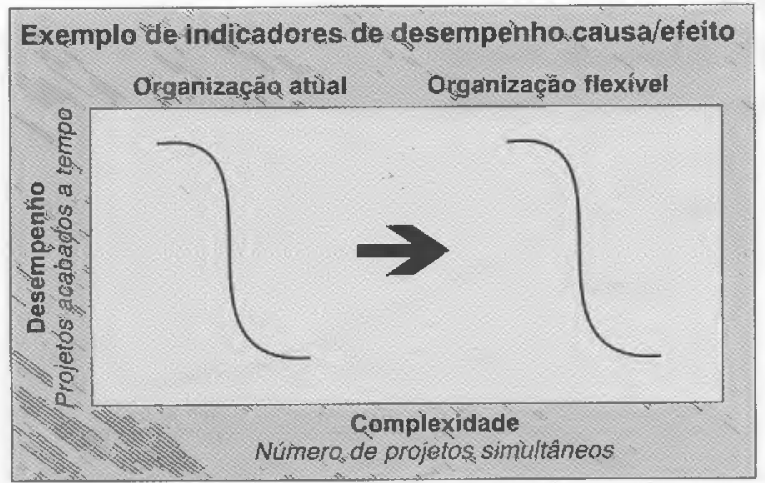




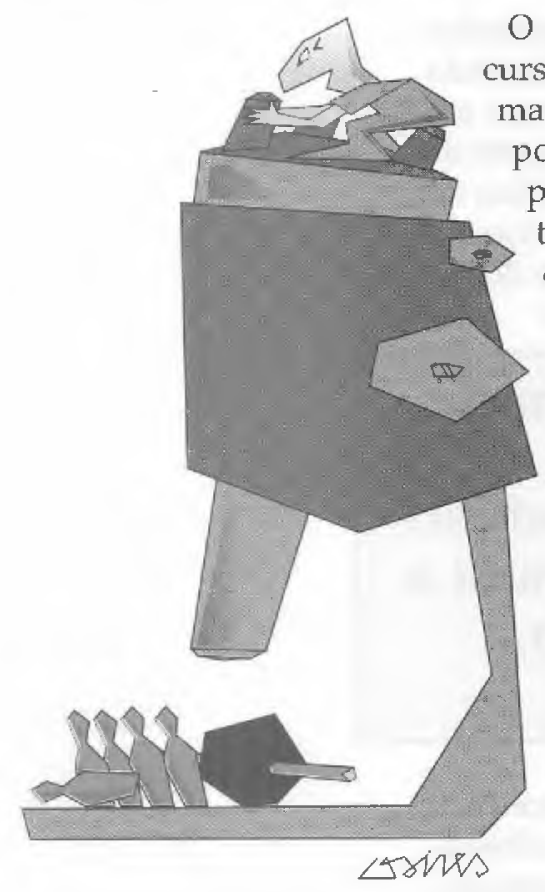

O gerente pode imaginar diversos cursos de açāo para remediar o problema de desempenho. A médio prazo, pode reduzir o número médio de projetos nos quais os engenheiros trabalham, realocando e destinando cada um dos engenheiros a menos projetos, contratando pessoal temporário ou reduzindo o número de projetos. A longo prazo, o gerente pode melhorar a flexibilidade da organização, isto é, deslocar a curva para a direita por exemplo, através de melhor planejamento, administração e controle do projeto.

\section{ANÁLISES ACIONADAS POR EVENTOS}

Os indicadores de desempenho fornecem aos gerentes medidas periódicas sobre a eficácia e a eficiência do processo de inovaçāo. Permitem que os gerentes acompanhem o progresso, por exemplo, ao rejuvenecer sua linha de produtos, mantendo-se dentro dos orçamentos de desenvolvimento, e reduzindo o tempo para o lançamento no mercado.

Os inovadores dinâmicos complementam essas medidas acionadas pelo calendário com análises acionadas por eventos. As análises acionadas por evento, que são ad hoc, são auditorias pormenorizadas de determinados aspectos do processo de inovaçāo. Um exemplo é uma análise póstuma de um projeto de desenvolvimento recém-concluído. Embora o gerente imprudente empreenda esforços desordenadamente onerosos para dar mais um passo, o gerente complacente se satisfaz em permanecer no nível de desempenho atingido.

\section{Figura 4}

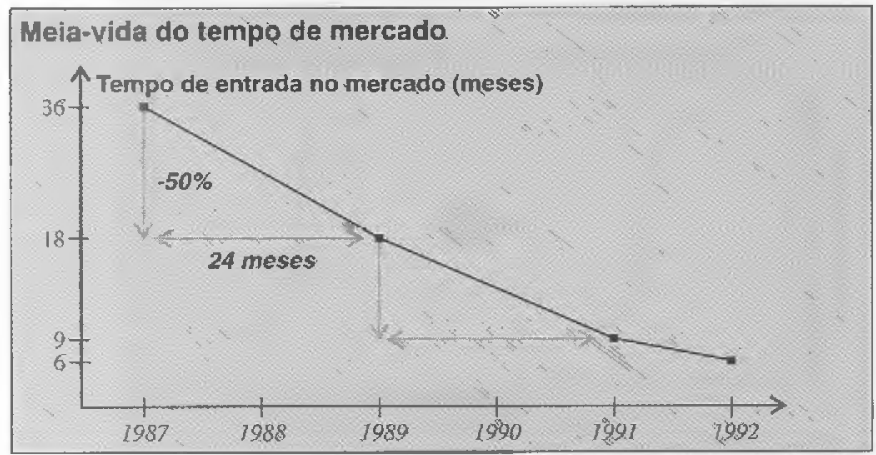

A razão para conduzir análises acionadas por eventos é que os indicadores de desempenho são a manifestaçāo das prioridades de inovação e interesses que foram considerados importantes por ocasiāo de sua concepção. À medida que o desempenho desses indicadores melhora, tornase cada vez mais difícil manter melhorias na mesma velocidade. O gerente complacente ficará satisfeito em permanecer no nível de desempenho atingido. $O$ gerente imprudente empreenderá esforços desordenadamente onerosos para dar um passo a mais.

Tanto a complacência como a imprudência são inapropriadas. É provável que, quando os níveis de desempenho se estabilizarem nos níveis objetivados, as prioridades de inovaçāo mudem ou devam mudar e, portanto, aqueles novos indicadores de desempenho são necessários. As análises acionadas por eventos permitem identificar esses indicadores mais adequados.

Por exemplo, a fábrica de semicondutores Analog Devices tem um sistema de indicadores de desempenho construído em torno da noçāo de meiavida. A companhia concluiu que o desempenho melhora $50 \%$ a cada período de tantos meses. Este período constante é denominado meia-vida. Por exemplo, a meia-vida da taxa de defeitos do produto é 10,4 meses. A meta de meia-vida para o tempo de entrada no mercado é 24 meses, o que significa que o tempo de entrada no mercado caiu de 36 meses em 1987 para 6 meses em 1992 (ver figura 4). Ainda que o tempo para entrada no mercado seja de importância crucial nesta implacável indústria, não pode ser reduzido infinitamente. Em algum ponto, a empresa precisa rever suas prioridades competitivas e focalizar alguma coisa mais, como a inovação do produto. Quando isso acontece, os indicadores de desempenho devem acompanhar.

A Arthur D. Little idealizou um conjunto de ferramentas de auditoria que ajudam os gerentes a mudar a forma como o processo de inovação é administrado e a adaptar os indicadores de desempenho correspondentes. Distinguimos três níveis de ferramentas, com base no impacto que elas têm na organização. Que pacote de ferramentas de auditoria deve ser aplicado em 
determinada situação depende dos objetivos e enfoques da análise (ver figura 5).

Ferramentas de nível 1

Uma ferramenta de nível 1 revela a percepção e o consenso da organização quanto ao ponto em que o processo de inovação precisa de melhorias. Constitui um espelho para a organização e abre seus olhos sobre a necessidade de mudança, às vezes de forma radical. Um exemplo da ferramenta de nível 1 é a pesquisa sobre a interface Marketing/Pesquisa \& Desenvolvimento. Este questionário testa a qualidade da interface entre o pessoal de Marketing e de Pesquisa \& Desenvolvimento em várias fases do processo de inovaçăo. Por exemplo, de que maneira os dois grupos estão envolvidos no desenvolvimento da estratégia de produto da empresa, na geraçăo de novas idéias de produto, no estabelecimento de prioridades de desenvolvimento avançado ou na especificaçăo de novos produtos?

Para se ver claramente onde e como mudar, devem-se usar também as ferramentas de nível 2 e nível 3 . Uma escala de melhores práticas ajuda a determinar o que significa ter "classe internacional" em termos de planejamento de projetos, ao usar regras de projeto, ao avaliar as necessidades do cliente ao estabelecer planos de ciclos do produto.

\section{Ferramentas de nível 2}

Uma ferramenta de nível 2 produz uma classificação das práticas da empresa no processo de inovação contra a melhor prática. Um exemplo é a escala de melhores práticas, uma matriz que define os níveis de desempenho a partir do "abertamente aceitável" até o de "classe internacional" para cada um dos aproximadamente 50 aspectos do processo de criação do produto. Por exemplo, a ferramenta ajuda a determinar o que significa ter "classe internacional" em termos de planejamento de projetos, no uso de regras de projeto, na avaliaçáu das necessidades do cliente e no estabelecimento de planos de ciclos do produto. Onde uma ferramenta de nível 2 revela que a atual prática da companhia se desvia muito da melhor prática, a companhia deve empreender uma investiga-

\section{Figura 5}

\begin{tabular}{|c|c|c|c|}
\hline \multicolumn{4}{|c|}{ Ferramentas para análises acionadas por eventos } \\
\hline & Veiculo & Produçằo & Impacto \\
\hline $\begin{array}{l}\text { Ferramentas } \\
\text { de nivel } 1\end{array}$ & Questionários & $\begin{array}{l}\text { Imagem refletida } \\
\text { da organizaçāo }\end{array}$ & Esclarecimento \\
\hline $\begin{array}{l}\text { Ferramentas } \\
\text { de nivel } 2\end{array}$ & $\begin{array}{l}\text { Entrevistas } \\
\text { estruturadas }\end{array}$ & $\begin{array}{l}\text { Classificaçāo contra } \\
\text { a melhor prática }\end{array}$ & Caso para mudança \\
\hline $\begin{array}{l}\text { Ferramentas } \\
\text { de nivel } 3\end{array}$ & $\begin{array}{l}\text { Seminários } \\
\text { estruturados }\end{array}$ & $\begin{array}{l}\text { Comparação com as } \\
\text { metas estratégicas }\end{array}$ & $\begin{array}{l}\text { Condiçōes para } \\
\text { mudança }\end{array}$ \\
\hline
\end{tabular}

ção e uma ação profundas. As ferramentas de nível 2 podem revelar oportunidades para melhorar consideravelmente o desempenho do processo de inovação.

\section{Ferramentas de nível 3}

Um exemplo de uma ferramenta de nível 3 é a "dissecação" do produto, a análise física e sistemática dos produtos da companhia e dos principais concorrentes. No caso do produto manufaturado, a "dissecação" do produto fornece referências e percepçôes detalhadas sobre as estruturas de custo, capacitação de projeto e oportunidades para melhorias nos projetos. Como essas análises são feitas através de várias funçōes, e estāo voltadas para as causas básicas do desempenho insuficiente, podem efetivamente criar uma ampla aceitação da necessidade de mudança.

\section{APRENDER A MEDIR, E MEDIR PARA APRENDER}

O ditado que diz "O que pode ser medido pode ser realizado" é verdadeiro somente em parte. A açāo intencional só acontece quando os canais de comunicação estão abertos e quando o espectro dos indicadores de desempenho é compatível com a tecnologia e as prioridades de inovação que a companhia escolheu seguir. A interpretaçăo, aprendizado e ajuste contínuos são necessários para se certificar de que as mediçōes dos indicadores de desempenho estimulam a inovação em uma dircçāo que reforce a posição competitiva da companhia.

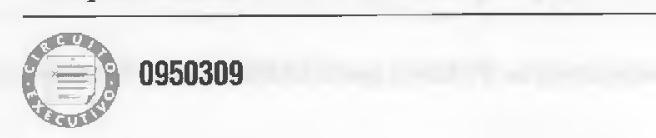

Artigo originalmente publicado na revista Prism, sob o título Measuring the performance of the innovation process. Traduzido por İntegra Traduçôes, revisto por José Tolovi Jr., Diretor Associado da Arthur D. Little Ltda. 